\title{
TRANSUTERINE MIGRATION AND EMBRYO SURVIVAL IN SHEEP
}

\author{
J. M. DONEY, R. G. GUNN AND W. F. SMITH \\ Hill Farming Research Organisation, Bush Estate, Penicuik, Midlothian EH26 OPH
}

(Received 9th February 1973)

The frequency with which transuterine migration of embryos occurs in sheep has been studied by a number of workers (Casida, Woody \& Pope, 1966; Baier \& Russe, 1968; Scanlon, 1972). When a single ovum is shed from one or both ovaries, the resultant embryo tends to be located in the associated horn of the uterus. When two or more ova are shed from a single ovary, migration of one embryo to the contralateral horn is the general rule, even when this uterine horn is not associated with a CL. There appears to be a greater loss of embryos in ewes with two CL in one ovary than in ewes with a single CL in each ovary, and although it has been suggested that migration is responsible for higher mortality, Sittmann (1972) considered that the available evidence did not support it. From studies on egg transfer in cattle, Rowson, Lawson \& Moor (1971) suggested that embryonic survival may be adversely affected by overcrowding but that location in a uterine horn not associated with a functional CL did not reduce viability.

The observations presented in this note were derived from a number of experiments concerned with the regulation of ovulation rate and embryonic survival in the Scottish Blackface and Cheviot breeds of sheep (e.g. Gunn, Doney \& Russel, 1972). Ewes were killed immediately on return to service or between 18 and 30 days after mating. The number and origin of potential embryos were determined by counting and sectioning the visible CL and all embryos were recorded as viable or non-viable. Non-viable embryos included degenerate but identifiable embryonic material and embryos whose crownrump length deviated significantly from the regression $L=1.9 \mathrm{~A}-23 \cdot 24$, where $\mathrm{L}$ is crown-rump length and $\mathrm{A}$ is age in days. This was derived from 685 measurements between 18 and 34 days of age. In practice, a difference of at least 4 days between actual and estimated age was accepted as indicative of retarded development over the whole range. The proportion of embryos identified as non-viable would increase with age at slaughter and the combined observations presented here will tend to underestimate total mortality. There appears to be little embryonic mortality after 30 days (Edey, 1969).

The results of observations on the uterine tracts of 467 ewes with two CL in one ovary and none in the other (ovulation type A), with one CL in each ovary (ovulation type B), or with a single CL (ovulation type C) are given in Table 1 . Considering only the fully identifiable cases and ignoring breed, as summarized in Table $2,84.8 \%$ of ewes with type-A ovulations showed a distributive migration resulting in the location of one embryo in each horn. 


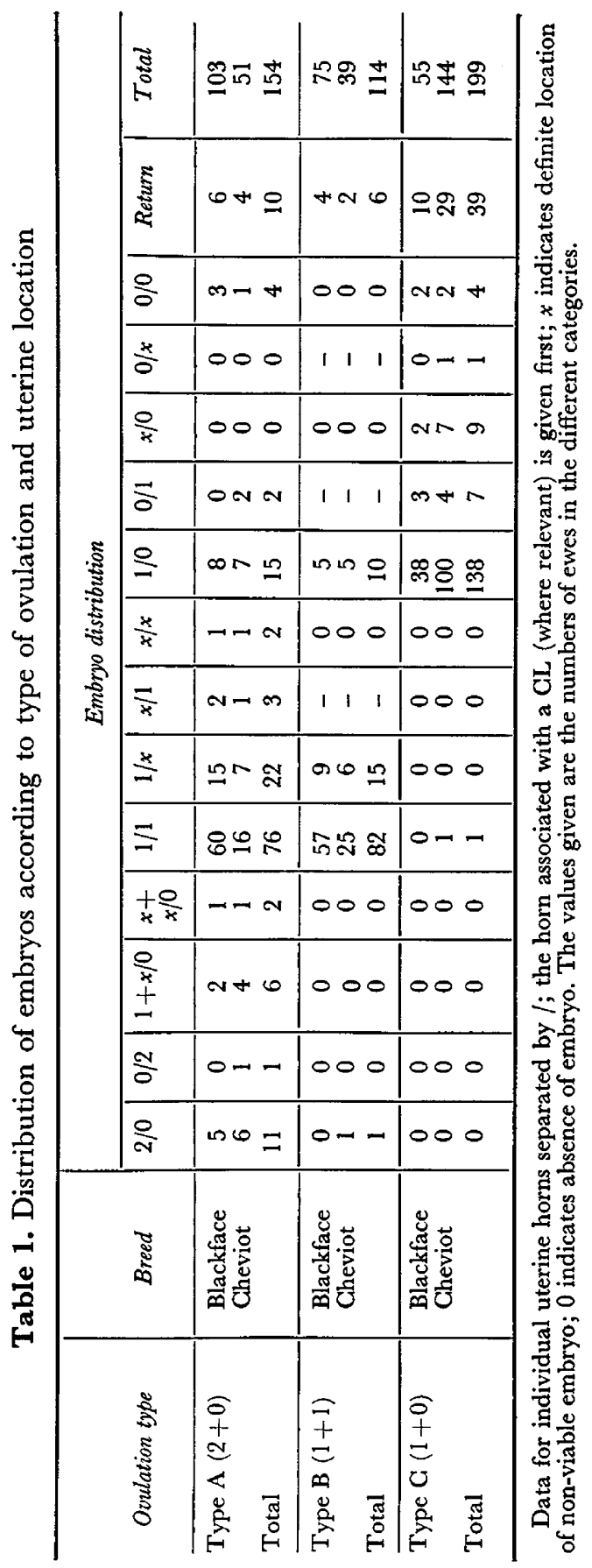


(One ewe was found with two CL in one ovary and two embryos in the opposite uterine horn.) Conversely, only one ewe $(1.0 \%)$ from type-B ovulators showed reverse migration resulting in embryo crowding. In type- $\mathrm{G}$ ovulators, the frequency of migration was found to be $5.2 \%$ and one ewe was found with a single CL but with an embryo in each horn. These values are in close agreement with those reported by Scanlon (1972). Since it may be argued that embryo survival may be affected either by multiple occupation of a single horn or by sole occupation of a horn not associated with a CL, the possible effect of the unidentifiable cases on the estimated frequency of migration must be considered. In these results, a large proportion of unidentifiable embryo locations was accounted for by ewes which returned to service within the normal cycle, which depends on failure of the conceptus before Day 12 (Moor \& Rowson, 1964; Edey, 1967). Embryo migration, however, does not take place until around the 14th day (Abnes \& Woody, 1971) so it is unrealistic to associate such returns to service with embryo migration.

Table 2. Summary of transuterine migration pattern in ewes according to ovulation type

\begin{tabular}{l|c|c|c|c|c|c|c|c|c}
\hline & \multicolumn{3}{|c|}{$A(2+0)$} & \multicolumn{3}{c|}{$B(1+1)$} & \multicolumn{3}{c}{$C(1+0)$} \\
\cline { 2 - 9 } & $\begin{array}{c}\text { No. of } \\
\text { Blackface }\end{array}$ & $\begin{array}{c}\text { No. of } \\
\text { Cheviot }\end{array}$ & Total & $\begin{array}{c}\text { No. of } \\
\text { Blackface }\end{array}$ & $\begin{array}{c}\text { No. of } \\
\text { Cheviot }\end{array}$ & Total & $\begin{array}{c}\text { No. of } \\
\text { Blackface }\end{array}$ & $\begin{array}{c}\text { No. of } \\
\text { Cheviot }\end{array}$ & Total \\
\hline No migration & 8 & 11 & 19 & 66 & 31 & 97 & 40 & 107 & 147 \\
Migration of one & 78 & $28 *$ & 106 & 0 & 1 & 1 & 3 & $5 \dagger$ & 8 \\
embryo & 11 & 8 & 19 & 5 & 5 & 10 & 2 & 2 & 4 \\
Indeterminate & 6 & 4 & 10 & 4 & 2 & 6 & 10 & 29 & 39 \\
Returns to service & 6 & 154 & 75 & 39 & 114 & 55 & 143 & 198 \\
\hline
\end{tabular}

$A, B, C=$ ovulation types (figures in parentheses indicate the numbers of CL in the respective ovaries).

* Includes one ewe with migration of both embryos.

$\dagger$ Excludes one ewe with two embryos from a single CL.

If the remaining unidentifiable cases are classified as either the common form of migration or non-migration, respectively, then approximate limits to the previously obtained proportions can be established. From the values given in Table 2, the incidence of migration from ovulation type $\mathrm{A}$ lies between $73.6 \%$ and $86.8 \%$, type $\mathrm{B}$ between $0.9 \%$ and $10.2 \%$ and type $\mathrm{C}$ between $5.0 \%$ and $7.5 \%$. Thus, inclusion of cases where prior embryonic mortality has prevented identification of location does not affect the conclusion that transuterine migration of embryos in sheep is a non-random process leading to spatial distribution.

The data can be used to consider the effect on embryo survival of type of ovulation, uterine distribution and presence or absence of a CL in the same horn. Ewes returning to service were excluded. From type-A ovulations, $22.2 \%$ of ova were non-viable as compared with $11.6 \%$ from type $\mathrm{B}$ and $8.8 \%$ from type C. Mortality in type A was significantly higher $(P<0.05)$ than in the other two types. Further calculations show that the mortality rate was $26.3 \%$ when 
two embryos were located in a single uterine horn. If all unidentified mortality was considered to result from non-migration, this value would become $43.4 \%$. The apparent mortality of embryos located as sole occupants of a uterine horn associated with an active CL was $6.7 \%, 7.8 \%$ and $6.7 \%$, respectively, from ovulation types $\mathrm{A}, \mathrm{B}$ and $\mathrm{G}$ (maximum rates $8.9 \%, 11.7 \%$ and $8.6 \%$ ). These differences were not significant. Location of a single embryo in a horn not associated with a CL (type-A migrants) gave a mortality of $22.9 \%$ (maximum $34.7 \%)$, significantly higher $(P<0.01)$ than the rate when located in a horn associated with a $\mathrm{CL}$.

Within ovulation type A, the difference between the mortality of migrant embryos $(22.9 \%)$ and that of embryos which remained together in the same uterine horn $(26.3 \%)$ was not significant but the overall mortality in ewes in which distributive migration occurred $(15.1 \%)$ was significantly lower $(P<0.05)$ than when both embryos remained in the same horn. Although the chances of survival of the migrant embryo were not improved, those of the non-migrant were, so that total mortality was reduced by the distributive process. In this series of observations, $57.4 \%$ of all double ovulations were found to occur in a single ovary. The trend was evident in all individual experiments and was significantly higher than the proportion occurring as one from each ovary.

Information concerning the distribution and fate of ova in thirty-five ewes with three or more CL was not suitable for detailed analysis but the tendency towards uterine distribution of embryos was maintained.

The proportion of single or multiple ovulations and of returns to service depended on experimentally imposed conditions at mating and the two breeds, therefore, are not comparable in these respects. There were, however, no indications to suggest that the treatments had any significant effect on embryo distribution. Only in type-A ovulations did the mortality rate differ significantly $(P<0 \cdot 1)$ between breeds $(28.7 \%$ and $19.7 \%$, respectively, for Cheviot and Blackface) but there was no significant difference between breeds in mortality according to location of embryos. Only $71.8 \%$ of unilateral double ovulations were associated with distributive embryonic migration in the Cheviot, however, as compared with $90.7 \%$ in the Blackface $(P<0.01)$. This suggests that although distributive migration is common in both breeds there may still be genetic differences in the extent to which it occurs.

These results, based on two breeds of hill sheep, support the suggestion that viability of sheep embryos is reduced both by uterine crowding and by location in a uterine horn not associated with a CL. Despite this, the high frequency of transuterine migration, found when two CL are present in a single ovary, does enhance embryo survival. There may be some genetic influence on the frequency of such migration.

\section{REFERENCES}

ABnes, F. B. \& Woody, C. O. (1971) Embryo migration in ewes. F. Anim. Sci. 33, 314 (Abstr.).

BAIER, W. \& Russe, I. (1968) Embryonic mortality in sheep after double ovulation. In: Proc. 6th Int. Congr. Anim. Reprod. \& A. I., Paris, Vol. 1, p. 397. Ed. C. Thibault. Institut National de la Recherche Agronomique, Jouy-en-Josas. 
CAsida, L. E., Woody, C. O. \& Pope, A. L. (1966) Inequality in function of the right and left ovaries and uterine horns of the ewe. F. Anim. Sci. 25, 1169.

Edey, T. N. (1967) Early embryonic death and subsequent cycle length in the ewe. F. Reprod. Fert. $13,437$.

EDEy, T. N. (1969) Prenatal mortality in the sheep: a review. Anim. Breed. Abstr. 37, 173.

GunN, R. G., Doney, J. M. \& Russel, A. J. F. (1972) Embryo mortality in Scottish Blackface ewes as influenced by body condition at mating and by post-mating nutrition. F. agric. Sci., Camb. $79,19$.

Moor, R. M. \& Rowson, L. E. A. (1964) Influence of embryo and uterus on luteal function in the sheep. Nature, Lond. 201, 522.

Rowson, L. E. A., Lawson, R. A. S. \& Moor, R. M. (1971) Production of twins in cattle by egg transfer. F. Reprod. Fert. 25, 261.

Scanlon, P. F. (1972) Frequency of transuterine migration of embryos in ewes and cows. F. Anim. Sci. 34, 791 .

Sittmann, K. (1972) Intrauterine migration and mortality of sheep embryos. Can. F. Anim. Sci. 52, 195. 